\title{
跨区域产业技术关联与产业创新 基于中国制造业的分析
}

\author{
钱肖颖 $1,2,3,4,5$, 孙斌栋 $1,2,3,4,5^{*}$ \\ (1. 华东师范大学中国行政区划研究中心, 上海 200241；2. 崇明生态研究院,上海 202162; \\ 3. 华东师范大学未来城市实验室, 上海 200241；4. 华东师范大学中国现代城市研究中心, 上海 200062; \\ 5. 华东师范大学城市与区域科学学院, 上海 200241)
}

\begin{abstract}
摘 要:产业分工联系是区域一体化的基础,但已有产业技术关联的文献主要关注区域内部, 缺乏对跨区域产业技 术关联的探究。由于中国省际产业联系数据难以获取, 论文运用引力模型和交叉熵法, 基于 2002、2007、2012年30 省的投人产出表拟合出省际产业贸易流量矩阵, 并进一步计算跨区域产业技术关联指数。跨区域产业技术关联呈 现不断加强的趋势, 尤其是城市群内部各地区产业之间的联系。基于 2002、2007、2012 年中国 30个省 16 个制造业 部门的面板数据, 使用固定效应模型进一步考察了跨区域产业技术关联对产业创新的影响。结果发现, 跨区域产 业技术关联有利于区域产业创新,但在本地产业技术联系较强的地区, 跨区域产业技术关联对产业创新的正效应 会被削弱, 本地产业技术关联和省际产业技术关联之间存在 “替代效应”, 知识产权的地方保护主义是导致这一结 果的可能原因。因此, 政策上应倡导扫清制度障碍、完善知识产权保护制度, 促进跨区域产业对本地的技术溢出, 进一步推动区域产业创新。
\end{abstract}

关 键 词: 技术关联; 本地联系; 跨区域联系; 区域产业创新; 投人产出

随着改革开放的深人, 中国近 $30 \mathrm{a}$ 制造业发展 迅猛, 逐步成长出一批大型企业。与此同时, 这些 企业的空间组织也发生了重大变化, 专业化分工变 得越来越普遍。企业基于市场、成本等因素的考 虑, 将其产品的生产过程分成若干个环节, 这些环 节被分散布局在不同地区 ${ }^{[1-2]}$ 。随着这种专业化分 工程度的不断加深, 基于企业的地区联系逐步演化 为基于产业的地区联系, 产业发展不再被局限于本 地, 而是与其他地区紧密联系 ${ }^{[3-4]}$ 。在这种背景下, 知识不仅来源于本地产业间的传递, 还来源于非本 地产业, 这种跨区域的知识溢出能够推动产业升级 和创新 ${ }^{[5]}$ 。因此, 跨区域产业之间的联系受到越来 越多的关注。

经济地理学观点认为地理邻近是推动产业发
展和创新的重要动力, 而演化经济地理学者则进一 步提出, 技术邻近比地理邻近更重要, 因此产业间 的技术邻近更有利于促进产业发展和创新, 相关的 理论研究和实证研究结论都支持这一观点 ${ }^{[6-10]}$ 。技 术邻近性为解释跨区域产业联系对地方产业发展 的作用提供了重要理论支撑。目前实证研究主要 从全球视角考察了跨国产业技术关联对本地产业 发展的影响 ${ }^{[11-13]}$,但忽视了国家内部地区间的产业 技术关联对经济活动的作用, 以及该作用是否会受 到本地产业技术关联的影响，即产业跨区技术关联 与本地技术关联之间是存在 “互补效应”还是 “替代 效应”。

基于此,本文基于中国省级行政区制造业的面 板数据, 定量检验省际产业技术关联对产业创新的

收稿日期:2019-11-15; 修订日期: 2020-03-24。

基金项目: 国家社会科学基金重大项目(17ZDA068)。[Foundation: Major Program of National Social Science Foundation of China, No.17ZDA068. ]

第一作者简介: 钱肖颖(1992-), 男, 江苏苏州人,博士生, 主要从事经济地理学方向研究。E-mail: qianxy77@163.com

*通信作者简介: 孙斌栋(1970-), 男,河北阜平人,教授,博士生导师, 主要从事城市地理与经济地理研究。

E-mail: bdsun@re.ecnu.edu.cn

引用格式: 钱肖颖, 孙斌栋. 跨区域产业技术关联与产业创新: 基于中国制造业的分析 [J]. 地理科学进展, 2020, 39(11): 1822-1831. [Qian Xiaoying, Sun Bindong. Interregional technological relatedness and industrial innovation: An analysis based on China's manufacturing industry. Progress in Geography, 2020, 39(11): 1822-1831. ] DOI: 10.18306/dlkxjz.2020.11.004 
影响, 以及该影响如何受到本地产业技术关联的调 节。本文研究对于地方产业政策制定具有重要参 考价值。

\section{1 跨区域产业技术关联和产业创新}

传统观点认为, 创新主体间在地理距离上的邻 近有利于知识溢出, 从而促进产业创新。演化经济 地理学则认为技术距离比地理距离对知识溢出更 重要。已有实证研究用产业间的技术关联表示技 术距离, 发现技术关联能够促进产业间的知识溢 出, 从而推动创新。Berge 等 ${ }^{[9]}$ 对欧盟地区生物技术 产业的实证研究发现, 与本地其他产业技术关联越 密的产业能够产生越多新知识和新专利。不少实 证研究支持了这一结论 ${ }^{[14-15]}$ 。

上述研究主要基于本地视角, 然而区域并非孤 立的,而是会与其他地区产生复杂的联系。类似于 本地产业的技术关联, 不同地区的产业同样可以因 为生产技术的相似或互补增进知识溢出, 以促进产 业创新。具体而言, 技术关联产业间的人才交流、 科研合作、企业投资和商品贸易能够获得更高效的 知识溢出 ${ }^{[16]}$ 。如技术关联产业间的人才交流或研 发合作因为知识基础相近, 更容易互相理解和沟 通，协作效率更高 ${ }^{[17]}$; 技术关联产业间的企业投资 因为行业背景相似, 更容易促进企业经营经验的输 出 ${ }^{[18]}$; 技术关联产业间的商品贸易则因为产品生产 技术接近, 更容易互相模仿 ${ }^{[19]}$ 。

但不同于本地产业关联, 跨区域产业关联会受 到地理距离和行政边界的限制, 由于距离成本和制 度壁垒等的存在, 使得跨区知识溢出面临阻力。在 这种情况下, 产业跨区知识溢出依旧产生的原因可 以分为 3 个方面。

一是区域分工的产生。随着企业生产规模的 不断扩大,生产过程被分割成若干生产阶段,一些 企业出于市场规模、生产成本等因素考虑, 将具有 技术关联的不同生产阶段分散布局在具有优势的 地区。随着这种产品内分工程度的日益加深, 基于 企业分工的跨区联系逐步演化为跨区产业联系 ${ }^{[1-2]}$, 地区产业因为生产分工而产生紧密的技术联系。 因此跨区产业关联是地区专业化分工的产物。

二是溢出知识的属性不同, 跨区产业更偏向于 编码知识的溢出。编码知识相对于隐性知识更容 易在空间上传播, 相对来说, 技术越密集、创新程度
越高的产业其越依赖于隐性知识,往往需要面对面 的交流, 知识的流动性较差, 因此这部分知识溢出 被固定在本地 ${ }^{[20]}$ 。而中国在 2013 年以前以低技术 纯加工产业为主, 这类产业技术和工艺更为成熟, 以编码知识为主, 被固化在设备和生产线上, 技术 创新少, 以产品创新为主, 随着专业化分工分散在 不同地区, 更容易产生跨区联系 ${ }^{[21]}$ 。

三是距离成本和制度壁垒的逐渐降低,使得知 识溢出阻力减少。政府对交通设施的投资改善、户 籍制度的放宽和国有企业的改革, 使得技术劳动力 在跨区流动上变得越加便捷频繁 ${ }^{[22]}$, 大大促进了产 业间的跨区技术溢出。

目前实证研究从全球视角考察了跨国产业技 术关联对本地产业发展的影响。Breschi 等 ${ }^{[20]}$ 指出 国家间通过商品贸易、技术工人流动、技术联盟、管 理经验交流等方式促进产业的区际联系,使得知识 在区域间流动。Andersson 等 ${ }^{[23}$ 对瑞士国际贸易的 研究发现, 跨国的产业关联能够促进本国产业复 苏, 与地区产业增长呈正相关。别的相关研究也得 出了相似的结论 ${ }^{[24]}$ 。

跨区域产业关联对创新的作用还可能受到本 地产业关联的影响, 本地产业关联的调节效应可能 存在正反 2 个方面, 即存在“互补效应”和“替代效 应”。一方面, 当某一产业与本地其他产业关联紧 密时, 能够扩大跨区产业知识溢出的范围, 通过本 地产业与跨区域产业间的技术合作,加强跨区域产 业对本地产业创新的推动作用 ${ }^{[25]}$, 即 “互补效应”; 另一方面,本地产业关联高的地区可能会阻碍跨区 产业间的知识溢出。在中国知识产权保护制度不 完善的背景下,地方保护普遍存在,地方政府更倾 向于保护本地企业知识产权,而非本地企业的知 识产权难以得到有效维护 ${ }^{[26]}$ 。因此, 当与本地产业 联系较紧密时,企业更倾向与本地供应链上的受 信任的单位进行技术合作,与非本地企业主要是知 识溢出较少的生产合作 ${ }^{[27]}$, 这一定程度上削弱了跨 区域产业关联对创新的推动作用, 即产生 “替代 效应”。

综上所述,已有跨区域产业技术关联的文献存 在 2 点不足:一是已有研究都是从跨国视角出发研 究跨区域产业关联对创新活动的影响, 忽略国家内 部地区间产业关联的影响;二是已有研究忽略了本 地产业关联与跨区域产业关联间的相互影响, 尤其 是当本地产业关联较强时,跨区域产业关联对创新 
活动的作用是否会受到影响。贺灿飞等 ${ }^{[21]}$ 考察了 相邻地区产业的影响, 发现相邻地区产业专业化与 本地产业关联交互项为正, 表明本地产业基础与相 邻地区产业相互促进, 能够推动新产品进人, 但该 研究有 2 点局限:一是仅关注了相邻地区产业的影 响, 但产业不一定仅与相邻地区产生联系; 二是没 有使用联系数据, 因为距离近的地区并不一定产业 联系就紧密。

为了弥补上述不足, 本文定量研究了中国国内 跨区域产业技术关联对产业创新的作用, 以及本地 产业技术关联和跨区域产业技术关联间的相互作 用。同时, 使用了联系数据, 运用投人产出表拟合 省际产业联系, 使产业跨区联系更真实; 本文还将 产业联系范围扩大到全国。基于以上分析, 本文提 出以下 2 个假设:

假设 1 : 跨区域产业技术关联有利于产业创新。

假设 2 : 本地产业技术关联会影响跨区域产业 技术关联对创新的作用, 即本地产业技术关联与跨 区域产业技术关联可能存在“互补效应”或“替代 效应”。

\section{2 方法与数据}

\section{1 产业技术关联测度}

常用的产业技术关联测度方法有 3 种: 一是基 于产业分类来衡量, 从属相同部门的产业视为技术 相关, 从属不同部门的产业视为技术不相关; 二是 基于两产业出现在同一地区的条件概率, 两产业出 现在同一地区的概率越高, 两产业间的技术越相 关; 三是基于投人产出表计算产业间的贸易关系， 两部门间贸易联系越多则越相关。前两者只能反 映全国层面的产业技术关联, 忽略了产业关联的地 区异质性。本文使用各省的投人产出表, 基于引力 模型拟合省际产业部门间的投人产出关系, 以反映 出不同地区产业技术关联的差异。

\subsection{1 拟合省际贸易流量}

由于目前没有直接的省际产业贸易数据, 只能 通过拟合获得, 因此本文借鉴李善同等 ${ }^{[28]}$ 的方法, 采用引力模型拟合省际贸易流量, 步骤如下:

首先, 构建引力模型拟合出城际产业间的商品 流动量, 模型如下: $\ln$ flow $_{k i, s, t}=\alpha+\beta_{1} \ln _{\text {output }}+\beta_{2} \ln _{\text {input }}+$ $\beta_{3} \ln \mathrm{GDP}_{k}+\beta_{4} \ln \mathrm{GDP}_{s}+\beta_{5} \ln \mathrm{Dis}_{k s}+\varepsilon$
式中: flow $_{k i, s j, t}$ 表示 $t$ 年(2002、2007、2012 年) $k$ 省 $i$ 产 业到 $s$ 省 $j$ 产业之间的商品贸易流量, 根据铁道部公 布的分商品省际铁路运输数据, 可获得与本文相关 的五类商品的铁路运输实物量, 该 5 类商品分别对 应相应的制造业如表 1 、表 2 , 将这些商品的省际运 输量作为省际贸易量 flow $_{k i, s j, t}$ 的替代。

output $_{k i}$ 和 input s $_{s j}$ 分别表示表示 $k$ 省 $i$ 产业的商 品流出量和 $s$ 省 $j$ 部门的商品流入量, 来自投人产出 表中与这些商品所对应的制造业部门的流人量和 流出量(流人流出量剔除了进口出口值)。 $\mathrm{GDP}_{k}$ 和 $\mathrm{GDP}_{s}$ 分别表示 $k$ 省和 $s$ 省的 GDP 占全国 GDP 的比 重, $\mathrm{Dis}_{k s}$ 表示两省省会城市之间的铁路运输距离。

其次, 将这些变量代人方程(1)中, 由于省际铁 路运输数据只有 2001-2008 年, 因此, 本文基于 2001-2008 年省际铁路运输数据面板数据, 并使用 固定效应, 通过对不同商品的回归分析, 得到回归 结果如表 1 。根据回归结果, 本文得到 5 类商品的 引力方程及对应的回归参数(表 2 )。

再次, 将各制造业产业的流出、流人量、GDP、 距离变量代人所对应商品的引力模型中, 得到拟合 的初始省际贸易流量值。

最后, 以投人产出表中的省际流人和流出量为 约束, 利用交叉摘法进行调整, 使得省间贸易流量 矩阵的行(列)和与相应省份产业的省际流出(人)相 等, 从而获得 30 省 16 个制造业部门之间的最终贸 易流量矩阵。

\subsection{2 省内与省际产业技术关联}

基于获得的最终贸易矩阵计算产业间的技术 关联度(TR)。因为贸易数据受到产业性质的影响, 如重工业部门本身产品单价高, 导致贸易总量大, 而轻工业部门因为产品单价低导致贸易总量小。 用贸易总量直接衡量产业间的关系会高估重工业产 业间的技术关联，低估轻工业产业间的技术关联。

因此,本文借鉴 Los 等 ${ }^{[29]}$ 的方法, 利用两产业间 贸易的相似系数, 即用余弦距离来衡量产业间的技 术关联,计算方法如下:

首先, 根据式(2)获得最终贸易矩阵计算直接消 耗系数。

$$
a_{k i, s j}=\frac{\text { flow }_{k i, s j}}{\text { flow }_{s j}}
$$

式中: $a_{k i, s j}$ 表示 $k$ 省 $i$ 产业到 $s$ 省 $j$ 产业的直接消耗 系数; flow ${ }_{s j}$ 表示 $s$ 省 $j$ 产业流人的商品贸易量。 
表 1 基于省际铁路运输的引力模型回归结果

Tab.1 Regression results of the gravity models based on interprovincial railway transportation

\begin{tabular}{|c|c|c|c|c|c|}
\hline \multirow{2}{*}{ 变量 } & \multicolumn{5}{|c|}{ ln flow } \\
\hline & 矿物性建筑材料 & 钢铁及有色金属 & 焦炭 & 石油 & 粮食 \\
\hline \multirow[t]{2}{*}{ ln output ${ }_{k i}$} & $0.176^{* * *}$ & $0.013^{* * * *}$ & $0.392^{\text {w*** }}$ & $0.152^{* * * *}$ & $0.628^{* *+*}$ \\
\hline & $(0.023)$ & $(0.005)$ & $(0.125)$ & $(0.062)$ & $(0.132)$ \\
\hline \multirow[t]{2}{*}{ ln input ${ }_{s j}$} & $0.125^{* * *}$ & $0.241^{* * * *}$ & $0.148^{* * *}$ & $0.152^{* * * *}$ & $0.135^{* * *}$ \\
\hline & $(0.052)$ & $(0.072)$ & $(0.056)$ & $(0.025)$ & $(0.031)$ \\
\hline \multirow[t]{2}{*}{$\ln \mathrm{GDP}_{k}$} & 0.124 & 0.012 & 0.112 & 0.012 & $0.413^{* *}$ \\
\hline & $(0.109)$ & $(0.009)$ & $(0.120)$ & $(0.009)$ & $(0.126)$ \\
\hline \multirow[t]{2}{*}{$\ln \mathrm{GDP}_{s}$} & 0.154 & 0.058 & 0.254 & 0.258 & 0.215 \\
\hline & $(0.125)$ & $(0.052)$ & $(0.157)$ & $(0.142)$ & $(0.172)$ \\
\hline \multirow[t]{2}{*}{$\ln \operatorname{Dis}_{k s}$} & $-0.814^{* * *}$ & $-0.758^{* * *}$ & $-0.628^{* *}$ & $-0.785^{* * *}$ & $-0.144^{* * *}$ \\
\hline & $(0.241)$ & $(0.135)$ & $(0.297)$ & $(0.152)$ & $(0.025)$ \\
\hline \multirow[t]{2}{*}{ 常数 } & $3.073^{* * * *}$ & $-2.361^{* * *}$ & $2.351^{* * * *}$ & $2.212^{* * * *}$ & $-0.729^{* * * *}$ \\
\hline & $(1.123)$ & $(0.851)$ & $(0.581)$ & $(0.812)$ & $(0.152)$ \\
\hline 观测样本 & 2400 & 2400 & 2400 & 2400 & 2400 \\
\hline$R^{2}$ & 0.421 & 0.373 & 0.392 & 0.401 & 0.315 \\
\hline
\end{tabular}

注: ***、**分别表示 $P<0.01 、 P<0.05$ 。

表 25 类商品与投入产出部门对照关系及其引力模型

Tab.2 Comparison of five commodities and input-output sectors and their gravity models

\begin{tabular}{|c|c|c|}
\hline 商品 & 制造业 & 引力模型 \\
\hline $\begin{array}{l}\text { 矿物性建筑 } \\
\text { 材料 }\end{array}$ & $\begin{array}{l}\text { 纺织业、服装皮革制品、木材加工、造纸印刷、 } \\
\text { 非金属制品 }\end{array}$ & $\ln$ flow $=3.073+0.176 \ln$ output $+0.125 \ln$ input $-0.814 \ln$ Dis \\
\hline $\begin{array}{l}\text { 钢铁及有色 } \\
\text { 金属 }\end{array}$ & $\begin{array}{l}\text { 金属冶炼加工、金属制品、通用设备、交用运 } \\
\text { 输设备、电气机械器材、通信设备、仪器仪表、 } \\
\text { 其他制造业 }\end{array}$ & $\ln$ flow $=-2.361+0.013 \ln$ output $+0.241 \ln$ input $-0.758 \ln$ Dis \\
\hline 焦炭 & 石油加工炼焦 & $\ln$ flow $=2.351+0.392 \ln$ output $+0.148 \ln$ input $-0.628 \ln$ Dis \\
\hline 石油 & 化学工业、石油加工业 & $\ln$ flow $=2.212+0.152 \ln$ output $+0.152 \ln$ input $+0.785 \ln$ Dis \\
\hline 粮食 & 食品制造及烟草加工 & $\ln$ flow $=-0.729+0.628 \ln$ output $+0.135 \ln$ input $+0.413 \ln \mathrm{GDP}_{k}-0.144 \ln$ Dis \\
\hline
\end{tabular}

其次, 基于直接消耗系数矩阵, 计算产业间的 技术关联指数。

$$
\mathrm{TR}_{k i, s j}=\frac{\sum_{m}\left(a_{m, k i} \times a_{m, s j}\right)}{\sqrt{\sum_{m} a_{m, k i}^{2} \times \sum_{m} a_{m, s j}^{2}}}
$$

式中: $a_{m, k i}$ 和 $a_{m, s i}$ 分别表示 $k$ 省 $i$ 产业和 $s$ 省 $j$ 产业 列向量的第 $m$ 个位置的直接消耗系数。如果 $k$ 省 $i$ 产业和 $s$ 省 $j$ 产业之间的技术关联度很高, TR 会接 近 1 。

技术关联(TR)只能反映两两产业间的技术关 联程度, 为了反映产业与本地其他产业以及跨省产 业间的技术关联强度, Hidalgo 等 ${ }^{[30]}$ 用产业关联密度 来刻画某一产业与地方其他所有产业的技术关联 强度, 本文参考 Hidalgo 等的方法, 构建了 2 个指数。

一是本地产业关联密度(LocRD), 刻画某一产 业与本地其他所有产业的技术关联强度。本地产
业关联密度计算方法如下：

$$
\operatorname{LocRD}_{k, i}=\frac{\sum_{j}\left(X_{k j} \times \mathrm{TR}_{i j}\right)}{\sum_{j} \mathrm{TR}_{i j}}
$$

式中: $\operatorname{LocRD}_{k, i}$ 为 $i$ 产业在 $k$ 省的技术关联密度; $X_{k j}$ 表示 $k$ 省 $j$ 产业是否具有比较优势(区位商大于 1 ), 若有取 1 , 否则取 0 。如果一个省内与 $i$ 产业相关的 大多数产品都具有比较优势, 那么 $i$ 行业与该省其 他产业关联性越高。

二是跨区域产业关联密度(InterRD), 刻画某一 产业与其他地区产业的技术关联强度。跨区域产 业关联密度计算方法如下：

$$
\operatorname{InterRD}_{k i}=\frac{\sum_{j}\left(X_{s j} \times \mathrm{TR}_{k i, s j}\right)}{\sum_{j} \mathrm{TR}_{k i, s j}}
$$

式中: InterRD ${ }_{k i}$ 表示 $k$ 省 $i$ 产业与其他省的产业技 
术关联密度; $X_{s j}$ 表示 $s$ 地区 $j$ 产业是否具有比较优 势(区位商大于 1 ), 若有取 1 , 否则取 0 。如果其他地 区与该地区 $i$ 产业相关的大多数产业都具有比较优 势, 那么该地区产业 $i$ 与其他地区产业关联性较高。

\section{2 模型和变量}

本文通过构造如下模型来检验跨地区产业技 术关联对产业创新的影响。具体模型设置如下:

$$
\begin{aligned}
\operatorname{Innov}_{r, i, t+1}= & f_{1}\left(\operatorname{InterRD}_{r, i, t}\right)+f_{2} \operatorname{control}_{r, i, t}+ \\
& \alpha_{r}+\alpha_{i}+\alpha_{t}+\varepsilon
\end{aligned}
$$

式中: 时间为 $t=2002 、 2007 、 2012$ 年, 因变量是区域 产业创新 $\left(\operatorname{Innov}_{r, i, t}\right)$, 定义为 $r$ 省 $i$ 产业新产品产值 占该行业总产值比重。根据中国工企数据库的定 义, 新产品指省内企业生产过程中首次采用新的生 产技术、新的设计, 或与之前相比具有重大改进的 产品。根据上述定义, 尽管外省其他企业可能进行 类似生产, 但是根据 $\mathrm{Lu}$ 等 ${ }^{[31]}$ 的结论, 对于中国这样 的发展中国家, 模仿在一定程度上也可以视为企业 进行产品创新的一个方面。同时, 由于在本文研究 阶段中行业发展以低技术的初加工产业为主导, 知 识溢出更偏向于固化与生产流程和设备的编码知 识, 这使得企业技术创新弱、产品创新强 ${ }^{[2]}$ 。最后, 本文还用人均专利申请数(Patent) 和劳动生产率 (Prod)作为创新的代理变量进行稳健性检验。人均 专利申请数为各省的行业专利申请数量与该行业 就业总人口比值, 表示为每千人专利申请数量; 劳 动生产率用地区该行业的总产值与该行业就业总 人口的比值表示。

核心变量 $\operatorname{InterRD}_{r, i, t}$ 表示地区 $r$ 产业 $i$ 的跨区 域产业关联密度, 预计回归系数为正。此外, 本文 控制了影响区域产业创新的其他变量, 包括本地产 业关联密度(LocRD)、地区产业专业化程度(LQ)、产 业总产值(Opt)、国有企业比重(SOE)、企业补贴率 (Subsidy)、企业研发投人率(R\&D)、对外贸易(Trade) 变量,具体如表 3 。

为了减轻模型中可能存在的内生性问题, 可以 将自变量滞后一年, 因变量使用2003、2008、2013年 的数据, 分别对应 2002,2007、2012年的解释变量。 同时, 本文面板数据模型采用固定效应, 加人地区 和产业虚拟变量以及时间趋势项, 以消除随时间不 变的遗漏变量。

\section{3 数据来源}

本文使用的产业关联数据来源于 2002、2007、
2012 年全国 30 个省份的投人产出表(不包括西藏、 香港、澳门和台湾); 省际铁路运输数据来源于铁道 部公布的《全国铁路统计资料汇编》(2002-2008 年); 进出口数据来源于海关进出口数据库 $(2002-$ 2012 年),将海关 8 位码与投人产出表的产业部门相 匹配; 专利数据来源于中国知识产权局 (http://cpquery.sipo.gov.cn/), 并根据产权局发布的《国际专利 分类与国民经济行业分类参考关系表》与投人产出 表中 16 个制造业部门相匹配。其他地区产业层面 数据主要来自于 2002-2013 年国家统计局中国工 业企业数据库的年度数据, 并根据行业代码与投人 产出表的产业部门相匹配。本文还使用了各省统 计年鉴(2002-2013 年)、《中国科技统计年鉴》对部 门缺失数据进行矫正和补足。

\section{3 描述性分析:省际产业关联与产业 创新}

本文考察了跨区产业关联与产业创新之间的 关系, 以及该关系如何受本地关联的影响。根据本 地产业关联密度的均值(0.199), 进一步将不同省份 分为本地产业关联高和本地产业关联低的地区(图 1)。总体看, 省际产业关联与新产品占比呈正相 关, 新产品占比较高的省份如重庆、北京、上海、天 津、浙江等, 其省际产业关联度也较高。分本地产 业关联看, 根据趋势线的斜率判断, 本地关联高的 地区, 省际产业关联对创新的正效益弱于本地关联 低的地区, 因此本地产业关联可能与省际产业关联 间存在“替代效应”, 本地产业关联会降低省际产业 关联对创新的促进作用。

其次, 从联系上看, 采用 Cytoscape 软件, 基于 省内和跨省 16 个制造业部门间的技术关联度, 本文 选取京津冀、长三角和东北三省 3 个区域, 构建 2012 年的区域产业技术关联图(图 2)。因为珠三角 主要是广东省内部产业间联系, 无法计算跨省的产 业技术关联,所以本文用东北三省取代珠三角城市 群。由图 2 可知, 京津冀、长三角和东北三省区域内 各省之间产业部门的技术关联均值分别为 0.037 、 $0.026 、 0.021$; 本地产业技术关联均值分别为 0.153 、 0.244、0.192。可见,京津冀地区跨区域产业关联较 其他地区更大, 而长三角地区本地产业关联较其他 区域更大,东北地区两者都较为平均。从新产品占 比看, 可以发现省际产业关联度高于均值(0.025)的 
表 3 模型中各类变量的描述性统计

Tab.3 Descriptive statistics of various variables in the model

\begin{tabular}{cllccrrr}
\hline & \multicolumn{1}{c}{ 变量 } & \multicolumn{1}{c}{ 变量解释 } & 平均值 & 标准差 & 最小值 & 最大值 \\
\hline 因变量 & Innov & 新产品产值占该行业总产值比重 & 0.174 & 0.037 & 0.087 & 0.316 \\
& $\ln$ Patent & 人均专利申请数 & 2.534 & 1.149 & -0.306 & 4.969 \\
& $\ln$ Prod & 人均GDP & 3.932 & 1.484 & 0.736 & 11.856 \\
核心变量 & InterRD & 跨区域产业关联密度 & 0.329 & 0.319 & 0.001 & 0.988 \\
控制变量 & LocRD & 本地产业关联密度 & 0.379 & 0.216 & 0.006 & 0.969 \\
& LQ & 地区产业的区位商 & 0.940 & 0.852 & 0.001 & 7.502 \\
& ln Opt & 地区产业总产值 & 15.482 & 2.088 & 6.605 & 19.845 \\
& SOE & 国有企业总产值占该产业总产值比重 & 0.413 & 0.232 & 0 & 1.000 \\
& Subsidy & 企业补贴收人与产业总产值的比值 & 0.006 & 0.010 & 0 & 0.078 \\
& R\&D & 地区产业的研发经费投人与总产值比重 & 0.070 & 0.049 & 0.007 & 0.487 \\
& Trade & 区产业进出口总额与工业总产值比值 & 0.134 & 0.169 & & 0 & 0.796 \\
\hline
\end{tabular}

产业, 新产品占比均值为 0.189 ; 而低于平均的产 业, 新产品占比均值为 0.118 。其中, 省际同行业间 的产业关联度均值为 0.042 , 新产品占比均值为 0.269 。因此, 省际产业关联程度高尤其是跨省同行 业关联程度越高的产业, 新产品占比也越高, 而新 产品占比较低的产业往往与相邻地区产业关联程 度较低。

\section{4 结果分析}

\section{1 基础回归分析}

回归结果如表 4 所示。模型 1 仅放人核心变 量, 模型 2 在模型 1 的基础上加人了控制变量, 模型 3 进一步加人了省际产业关联和本地产业关联的交 互项, 为基准模型。所有模型都采用了固定效应, 以缓解遗漏变量导致的内生性。

首先, 跨区域产业关联密度 InterRD 在模型 2 中 系数显著为正, 表明与其他地区产业的联系越紧

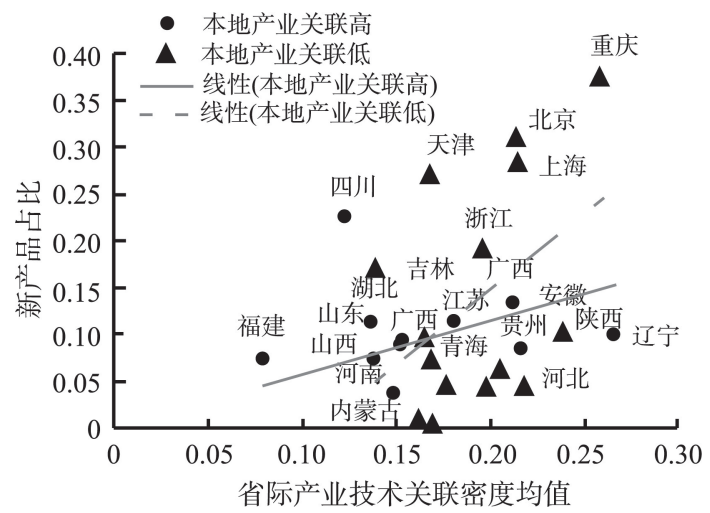

图 1 省际产业技术关联与产业创新(2012年)

Fig.1 Interregional technological relatedness and industrial innovation, 2012
密,越有利于该产业创新, 跨区域产业关联密度每 增长 1 个标准差, 新产品占比提高 $3.6 \%(0.319 \times$ $0.114 \approx 3.6 \%$ )。其原因在于与其他地区技术关联紧 密的产业,在跨区域贸易、人才流动和管理经验交 流时能产生更高的知识溢出效率, 获得更多隐性知 识 ${ }^{[16]}$,这验证了假设 1 。

其次, 从交互项看, 跨区域产业关联密度和本 地产业关联密度和的交互项 InterRD $\times$ LocRD 系数 显著为负, 表明在本地产业关联强的地区,跨区域 产业关联对创新的促进作用会被降低,即本地产业 关联和省际产业关联间存在“替代效应”,结论符合 假设 2 的推断。可能原因是, 本地关联强的产业, 出 于信任和技术保护的考虑，企业更倾向于选择与本 地产业进行技术合作, 以减少跨区域合作中的技术 溢出,从而保护自身专利技术 ${ }^{[2]}$ 。

最后, 为了检验结果的稳健性, 考虑到对因变 量区域产业创新的多种测度方式, 模型 4 用劳动生 产率Prod 替换因变量, 模型 5 用人均专利申请量 Patent 替换因变量。变量系数和符号与原结论一 致,结果稳健。

\section{2 分地区异质性检验}

为了进一步检验结果的异质性和稳健型, 本文 将样本按照地区进行分组,模型同样采用了固定效 应, 回归结果见表 5。可见,跨区域产业关联对产业 创新的影响主要体现在东部、中部和西部, 而东北 地区不明显。比较各地区系数, 东部地区 InterRD 系数最大, 表明东部地区省际产业关联对产业创新 的推动作用较其他地区强。从交互项看, 中部地区 较东、西部地区, 本地产业关联的削弱作用更强, 表 明中部地区较东、西部地区有更强的本地偏好。 


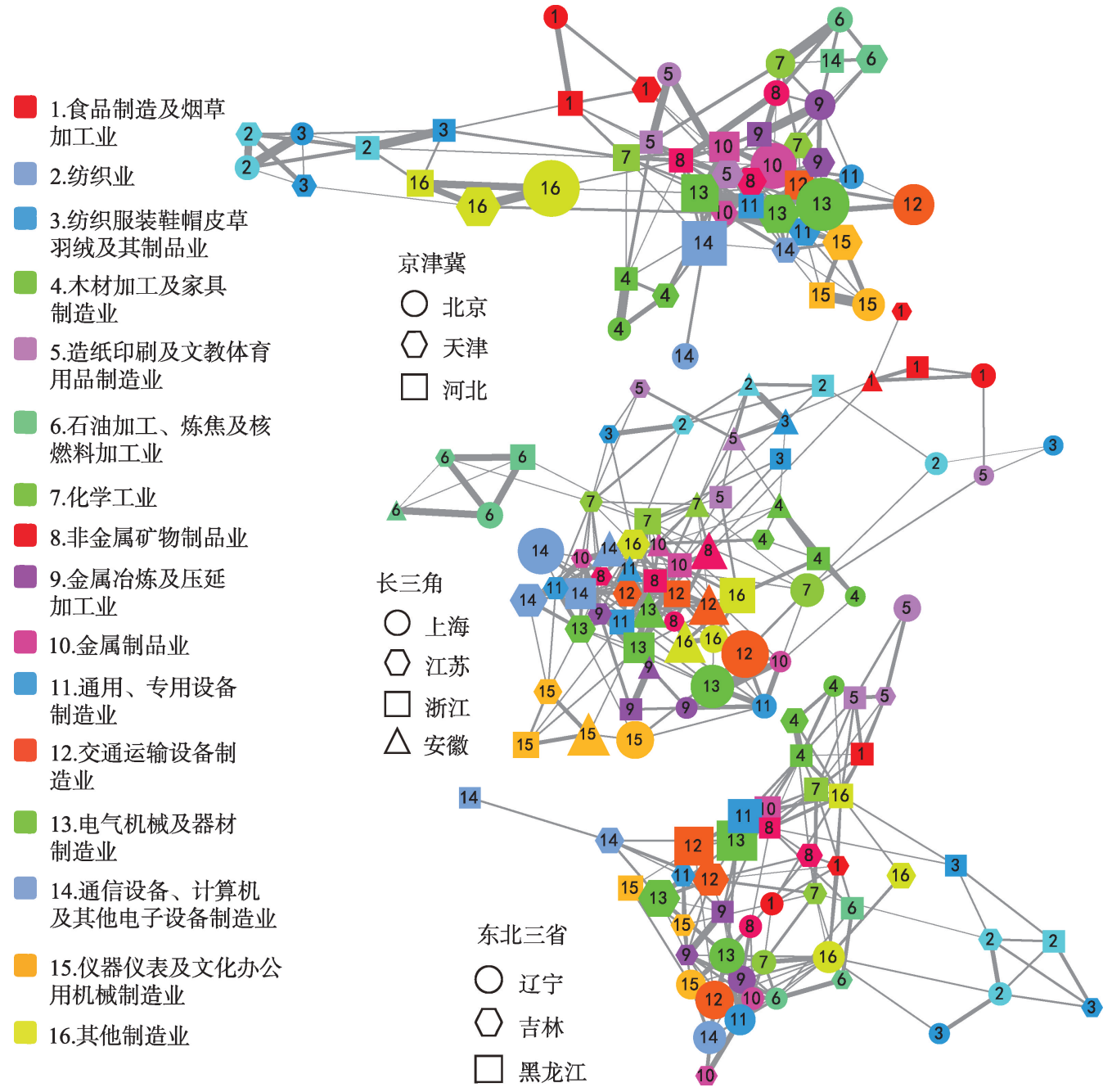

注:图中每个点代表各省的某一制造业部门,点的大小代表该产业的新产品产值占比,线代表产业间的技术 关联。采用边缘加权(Edge-weighted spring embedded layout), 并去除新产品产值占比为 0 和产业关联度小于 0.1 的边,最后得到该图。

图 2 分地区产业技术关联与产业创新(2012年)

Fig.2 Technological relatedness and industrial innovation in subregions, 2012

\section{5 结论与讨论}

基于 2002、2007 和 2012 年中国省级行政区制 造业面板数据, 本文采用固定效应模型, 从地区一 产业层面检验跨区域产业关联对产业创新的作用， 以及该影响如何受到本地产业联系的调节。主要 结论如下:

(1) 跨区域产业技术关联有利于区域产业创 新,这验证了本文假说 1 。

(2) 本地产业技术关联会削弱省际产业关联对 创新的推动作用, 本地产业技术关联和省际产业技 术关联间存在 “替代效应”, 验证了本文假说 2 , 知识 产权的地方保护主义是可能的原因。
（3）产业技术关联对创新的影响存在地区异质 性,东部地区跨区域产业技术关联对创新的推动作 用较其他地区更强，而中部地区跨区域产业技术关 联对创新影响受本地产业技术关联的削弱更强。

实现区域一体化的关键在于促进区域协调发 展, 而加强区域间的产业联系是可行之策。在自身 能力不足时, 跨区域联系能够帮助本地产业通过学 习其他地区的先进技术来获得自身创新发展, 这一 点对落后地区尤为重要。但本文也发现本地和跨区 域产业联系间存在 “替代效应”, 知识产权的地方保 护使企业为了降低风险而选择与本地产业进行技术 合作, 而异地产业仅选择生产分工, 这会导致产业跨 区域联系时的知识溢出数量减少和效率降低。因 
表 4 基本回归结果以及稳健性检验

Tab.4 Basic regression results and robustness test

\begin{tabular}{|c|c|c|c|c|c|}
\hline \multirow{3}{*}{ 变量 } & \multicolumn{3}{|c|}{ 基本回归 } & \multicolumn{2}{|c|}{ 稳健检验 } \\
\hline & 模型 1 & 模型 2 & 模型 3 & 模型 4 & 模型 5 \\
\hline & Innov & Innov & Innov & Prod & Patent \\
\hline \multirow[t]{2}{*}{ InterRD } & $0.145^{* * *}$ & $0.114^{* *}$ & $0.153^{* * * *}$ & $1.072^{* * * *}$ & $0.286^{* *+}$ \\
\hline & $(0.038)$ & $(0.056)$ & $(0.050)$ & $(0.227)$ & $(0.101)$ \\
\hline \multirow[t]{2}{*}{ LocRD $\times$ InterRD } & & & $-0.076^{* * *}$ & $-0.523^{* * *}$ & $-0.546^{*}$ \\
\hline & & & $(0.017)$ & $(0.364)$ & $(0.540)$ \\
\hline \multirow[t]{2}{*}{ LocRD } & $0.149^{* * * *}$ & $0.116^{*}$ & $0.138^{* * *}$ & $0.857^{* * *}$ & $0.405^{* *+}$ \\
\hline & $(0.052)$ & $(0.038)$ & $(0.059)$ & $(0.201)$ & $(0.031)$ \\
\hline \multirow[t]{2}{*}{ LQ } & & $0.018^{* * * *}$ & $0.017^{* * * *}$ & $1.305^{* * *}$ & $4.468^{* * * *}$ \\
\hline & & $(0.002)$ & $(0.002)$ & $(0.052)$ & $(0.094)$ \\
\hline \multirow[t]{2}{*}{ Opt } & & $0.009^{* * *}$ & $0.008^{* * * *}$ & $0.045^{* * *}$ & $2.081^{* *+}$ \\
\hline & & $(0.001)$ & $(0.001)$ & $(0.014)$ & $(0.023)$ \\
\hline \multirow[t]{2}{*}{ SOE } & & 0.003 & 0.002 & $-0.275^{* * *}$ & $-3.788^{* *}$ \\
\hline & & $(0.004)$ & $(0.004)$ & $(0.088)$ & $(0.140)$ \\
\hline \multirow[t]{2}{*}{ Subsidy } & & $0.529^{* * * *}$ & $0.512^{* * * *}$ & $11.318^{* * *}$ & -1.809 \\
\hline & & $(0.084)$ & $(0.080)$ & $(2.239)$ & $(2.933)$ \\
\hline \multirow[t]{2}{*}{ R\&D } & & $0.093^{* * * *}$ & $0.089^{* * * *}$ & $23.807^{* * *}$ & $2.229^{* *+}$ \\
\hline & & $(0.019)$ & $(0.018)$ & $(0.520)$ & $(0.577)$ \\
\hline \multirow[t]{2}{*}{ Trade } & & $0.035^{* * *}$ & $0.038^{* * * *}$ & $1.769^{* * * *}$ & $0.779^{* * *}$ \\
\hline & & $(0.005)$ & $(0.006)$ & $(0.146)$ & $(0.208)$ \\
\hline \multirow[t]{2}{*}{ 常数 } & $0.141^{* * * *}$ & -0.004 & -0.003 & -0.148 & $-12.558^{* * *}$ \\
\hline & $(0.003)$ & $(0.009)$ & $(0.009)$ & $(0.227)$ & $(0.341)$ \\
\hline 观测样本 & 1440 & 1440 & 1440 & 1440 & 1440 \\
\hline 省份 & 30 & 30 & 30 & 30 & 30 \\
\hline$R^{2}$ & 0.418 & 0.651 & 0.663 & 0.922 & 0.691 \\
\hline
\end{tabular}

注: 回归模型加人地区、产业虚拟变量和时间趋势项,并使用稳健标准误; ***、**、分别表示 $P<0.01 、 P<0.05 、 P<0.1$ 。下同。

表 5 分地区异质性检验回归结果

Tab.5 Results of heterogeneity test grouped by regions

\begin{tabular}{lcccc}
\hline \multicolumn{1}{c}{ 变量 } & 东部 & 中部 & 西部 & 东北 \\
\hline InterRD & $0.168^{* * * *}$ & $0.151^{* * *}$ & $0.045^{* *}$ & 0.041 \\
& $(0.057)$ & $(0.050)$ & $(0.021)$ & $(0.043)$ \\
InterRD×LocRD & $-0.083^{* * * *}$ & $-0.111^{* * *}$ & $-0.065^{*}$ & -0.012 \\
& $(0.024)$ & $(0.033)$ & $(0.038)$ & $(0.072)$ \\
LocRD & $0.139^{* * * *}$ & $0.161^{* * *}$ & $0.027^{*}$ & 0.037 \\
& $(0.055)$ & $(0.070)$ & $(0.015)$ & $(0.038)$ \\
控制变量 & 包含 & 包含 & 包含 & 包含 \\
常数 & -0.008 & 0.026 & 0.004 & 0.040 \\
& $(0.018)$ & $(0.031)$ & $(0.013)$ & $(0.035)$ \\
观测样本 & 480 & 288 & 528 & 144 \\
省份 & 10 & 6 & 11 & 3 \\
$R^{2}$ & 0.692 & 0.736 & 0.841 & 0.829 \\
\hline
\end{tabular}

此, 政府需要不断完善知识产权保护制度, 减少地方 保护主义, 保障本地企业和跨区企业的知识产权, 给 企业跨区合作创造更容易彼此互信的创新环境。
本文研究存在 2 点不足之处:一是由于贸易数 据难于获取, 只能通过间接估算获得, 可能与实际 存在一定偏差 $;$ 二是投人产出表数据只有省份数 据,跨区域产业间的产业关联更多依托城市,而用 省际产业关联无法涵盖城市间产业关联的特征。 这些问题将在未来数据可得后通过进一步研究得 到解决。

\section{参考文献(References)}

[1] 盛科荣, 张红霞, 赵超越. 中国城市网络关联格局的影响 因素分析: 基于电子信息企业网络的视角 [J]. 地理研 究, 2019, 38(5): 1030-1044. [Sheng Kerong, Zhang Hongxia, Zhao Chaoyue. Determinants of the urban spatial network in China: An analysis through the lens of corporate networks within electronic information industry. Geographical Research, 2019, 38(5): 1030-1044. ]

[2] Taylor P J, Derudder B. World city network: A global urban analysis [M]. London, UK: Routledge, 2015. 
[3] Dicken P, Kelly P F, Olds K, et al. Chains and networks, territories and scales: Towards a relational framework for analysing the global economy [J]. Global Networks, 2001, 1(2): 89-112.

[4] Capello R. The city network paradigm: Measuring urban network externalities [J]. Urban Studies, 2000, 37(11): 1925-1945.

[5] Yeung H W, Liu W, Dicken P. Transnational corporations and network effects of a local manufacturing cluster in mobile telecommunications equipment in China $[\mathrm{J}]$. World Development, 2006, 34(3): 520-540.

[6] 贺灿飞, 黎明. 演化经济地理学 [J]. 河南大学学报(自然 科学版), 2016, 46(4): 387-391. [He Canfei, Li Ming. Evolutionary economic geography. Journal of Henan University (National Science), 2016, 46(4): 387-391. ]

[7] Boschma R. Relatedness as driver of regional diversification: A research agenda [J]. Regional Studies, 2016, 51 (3): 351-364

[8] 贺灿飞. 区域产业发展演化: 路径依赖还是路径创造? [J]. 地理研究, 2018, 37(7): 1253-1267. [He Canfei. Regional industrial development and evolution: Path dependence or path creation? Geographical Research, 2018, 37 (7): 1253-1267. ]

[9] Berge M V D, Weterings A. Relatedness in eco-technological development in European regions [R]. Papers in Evolutionary Economic Geography (PEEG) 1413. Utrecht, Netherland: Utrecht University, Department of Human Geography and Spatial Planning, Group Economic Geography, 2014.

[10] Neffke F, Henning M, Boschma R. How do regions diversify over time? Industry relatedness and the development of new growth paths in regions [J]. Economic Geography, 2011, 87(3): 237-265.

[11] 史进. 全球和地方力量对中国城市制造业增长的影响 [J]. 地理科学进展, 2019, 38(10): 1571-1582. [Shi Jin. Global and local factors of city growth in China based on the change in the manufacturing sector. Progress in Geography, 2019, 38(10): 1571-1582. ]

[12] 毛熙彦, 贺灿飞. 区域发展的“全球一地方”互动机制研 究 [J]. 地理科学进展, 2019, 38(10): 1449-1461. [Mao Xiyan, He Canfei. A review of global-local interactions for regional development. Progress in Geography, 2019, 38(10): 1449-1461. ]

[13] 黎诗扬, 朱华晟, 丁玥. 国际贸易对地区劳动力技能升 级的影响: 基于中国大陆地区地级市的数据分析 $[\mathrm{J}]$. 地理科学进展, 2019, 38(10): 1514-1522. [Li Shiyang, Zhu Huasheng, Ding Yue. The impact of international trade on regional skill upgrading: Analysis of prefecture- level cities in the mainland of China. Progress in Geography, 2019, 38(10): 1514-1522. ]

[14] 王俊松. 相关性多样化、内外资联系与城市创新能力 [J]. 南方经济, 2015(12): 55-70. [Wang Junsong. Related variety, extraregional linkages and urban innovation ability. South China Journal of Economics, 2015(12): 55-70. ]

[15] Boschma R, Heimeriks G, Balland P. Scientific knowledge dynamics and relatedness in biotech cities [J]. Research Policy, 2014, 43(1): 107-114.

[16] 赵勇, 白永秀. 知识溢出: 一个文献综述 [J]. 经济研究, 2009(1): 144-156. [Zhao Yong, Bai Yongxiu. Knowledge spillovers: A survey of the literature. Economic Research Journal, 2009(1): 144-156. ]

[17] Almeida P, Kogut B. Localization of knowledge and the mobility of engineers in regional networks [J]. Manage Science, 1999, 45(7): 905-917.

[18] Hussler C. Culture and knowledge spillovers in Europe: New perspectives for innovation and convergence policies? [J]. Economics of Innovation and New Technology, 2004, 13(6): 523-541.

[19] Keller W. Geographic localization of international technology diffusion [J]. America Economic Review, 2002, 92(1): 120-142.

[20] Breschi S, Lissoni F. Knowledge spillovers and local innovation systems: A critical survey $[\mathrm{J}]$. Social Science Electronic Publishing, 2000, 10(4): 975-1005.

[21] 贺灿飞, 任永欢, 李蕴雄. 产品结构演化的跨界效应研 究: 基于中国地级市出口产品的实证分析 [J]. 地理科 学, 2016, 36(11): 1605-1613. [He Canfei, Ren Yonghuan, Li Yunxiong. The mechanism of cross- boundary product evolution in China: An empirical analysis based on export product of prefecture-level cities. Scientia Geographica Sinica, 2016, 36(11): 1605-1613. ]

[22] 纪韶, 朱志胜. 中国省际劳动力流动的特征演变及经济 合理性研究: 1995-2010 [J]. 经济与管理, 2013, 27(8): 20-26. [Ji Shao, Zhu Zhisheng. Study on the feature and economic rationality of inter- provincial labor flows in China: 1995-2010. Economy and Management, 2013, 27 (8): 20-26. ]

[23] Andersson M, Bjerke L, Karlsson C. Import flows: Extraregional linkages stimulating renewal of regional sectors? [J]. Environment Planning A, 2013, 45(12): 2999-3017.

[24] Zhu S, He C. Upgrading in China's apparel industry: International trade, local clusters and institutional contexts [J]. Post Communist Economies, 2018. doi: 10.1080/ 14631377.2017.1362099.

[25] Boschma R, Martín V, Minondo A. Neighbour regions as 
the source of new industries [J]. Paper in Regional Science, 2017, 96(2): 227-245.

[26] 龙小宁, 王俊. 中国司法地方保护主义: 基于知识产权 案例的研究 [J]. 中国经济问题, 2014(3): 3-18. [Long Xiaoning, Wang Jun. Local judicial protectionism in China: An empirical study of people's supreme court IP cases. China Economic Studies, 2014(3): 3-18. ]

[27] 行伟波, 李善同. 本地偏好、边界效应与市场一体化: 基 于中国地区间增值税流动数据的实证研究 [J]. 经济学 (季刊), 2009, 8(4): 1455-1474. [Xing Weibo, Li Shantong. Home biases, border effects and market integration: An empirical study based on inter-provincial. China Economic Quarterly, 2009, 8(4): 1455-1474. ]
[28] 李善同. 2002 年中国地区扩展投人产出表 [M]. 北京: 经济科学出版社, 2010. [Li Shangtong. Input output table of China's regional expansion in 2002. Beijing, China: Economic Science Press, 2010. ]

[29] Los B, Verspagen B. R\&D spillovers and productivity: Evidence from U.S. manufacturing microdata [J]. Empirical Economics, 2000, 25(1): 127-148.

[30] Hidalgo C A, Klinger B, Barabasi A L, et al. The product space conditions the development of nations [J]. Science, 2007, 317: 482-487.

[31] Lu J, Tao Z. Trends and determinants of China's industrial agglomeration [J]. Journal of Urban Economics, 2009, 65(2): $167-180$

\title{
Interregional technological relatedness and industrial innovation: An analysis based on China's manufacturing industry
}

\author{
QIAN Xiaoying ${ }^{1,2,3,4,5}$, SUN Bindong ${ }^{1,2,3,4,5^{*}}$ \\ (1. Center for Studies of Administrative Division of China, East China Normal University, Shanghai 200241, China; \\ 2. Institute of Eco-Chongming, Shanghai 202162, China; \\ 3. Future City Lab, East China Normal University, Shanghai 200241, China; \\ 4. The Center for Modern Chinese City Studies, East China Normal University, Shanghai 200062, China; \\ 5. School of Urban and Regional Science, East China Normal University, Shanghai 200241, China)
}

\begin{abstract}
Geographic proximity arising from industrial agglomeration can promote firm innovation and thereby industrial development. Scholars of evolutionary economic geography further propose that technology proximity is more important than geographic proximity, which provides essential theoretical support for explaining the role of interregional industrial linkages in local industrial development. However, the existing literature mainly focuses on the technological relatedness within regions but lacks research for interregional relatedness, especially the effects of interregional technology relatedness on regional innovation. Based on the input-output panel data of 2002, 2007, and 2012 from 30 provinces of the mainland of China, this study used the gravity model and cross- entropy method to fit the interprovincial trade flow matrix of the industries and further computed the index of intraregional and interregional technological relatedness. This study then used a two-way fixed effect model to examine the effects of intraregional and interregional technological relatedness on industrial innovation based on the data of 16 manufacturing sectors in 30 provinces in 2002, 2007, and 2012. First, the results show that the degree of interregional technological relatedness of industries has been strengthened, especially the linkages within city agglomerations. Second, interregional technological relatedness of industries has a positive effect on industrial innovation, but local technological relatedness of industries would weaken this positive effect. Therefore, the government should remove institutional barriers and encourage the inter- or intraregional industrial linkages that promote regional industrial innovation.
\end{abstract}

Keywords: technological relatedness; intraregional relatedness; cross-regional relatedness; regional industrial innovation; input-output 